\title{
3-Phenyl-4-Acyl-5-Isoxazolones as Reagents for Liquid-Liquid Extraction of Tetravalent Zirconium and Hafnium from Acidic Chloride Solutions
}

\author{
B. Ramachandra Reddy, ${ }^{*, a}$ J. Rajesh Kumar ${ }^{b}$ and A. Varada Reddy ${ }^{b}$ \\ ${ }^{a}$ Inorganic Chemistry Division, Indian Institute of Chemical Technology (CSIR), Hyderabad, 500007 A.P., India \\ ${ }^{b}$ Analytical Chemistry Division, Department of Chemistry, Sri Venkateswara University, Tirupati, 517502 A.P., India
}

\begin{abstract}
Extração líquido-líquido de zircônio e háfnio tetravalentes, a partir de soluç̃os de ácido clorídrico, foi investigada usando-se 3-fenil-4-acil-5-isoxazolonas em xileno, tais como 3fenil-4-benzoil-5-isoxazolonas (HPBI), 3-fenil-4-(4-fluorobenzoil)-5-isoxazolona (HFBPI) e 3-fenil-4-(4-toluoil)-5-isoxazolona (HTPI). A extração de zircônio(IV) / háfnio(IV) mostrou um mecanismo de troca iônica: $\mathrm{MO}^{2+}{ }_{(\text {aq) }}+2 \mathrm{HA}_{(\text {org })} \leftrightarrow \mathrm{MOA}_{2 \text { (org) }}+2 \mathrm{H}_{(\text {aqq }}^{+}$, onde $\mathrm{M}$ $=\mathrm{Zr}(\mathrm{IV}) / \mathrm{Hf}(\mathrm{IV})$ e HA = HPBI ou HFBPI ou HTPI. A variação dos valores D (razão $\left[\mathrm{MOA}_{2}\right]_{(\text {org }} /\left[\mathrm{MO}^{2+}\right]_{\text {(aq) }} ;$ prováveis espécies em equilíbrio durante a extração) com o aumento da concentração ácido/extrator mostrou um gráfico linear com inclinação 2 . O efeito da natureza dos diluentes, como tetracloreto de carbono, ciclohexano, $n$-hexano, benzeno, nitrobenzeno, xileno, tolueno e clorofórmio na extração de zirônio(IV) / háfnio(IV) foi estudado. O comportamento da extração de zircônio(IV) / háfnio(IV) foi também comparado com o de outros íons metálicos, como titânio(IV), alumínio(III) e ferro(III), e pode, genericamente, ser aplicado aos íons metálicos estudados.
\end{abstract}

Liquid liquid extraction of tetravalent zirconium and hafnium from acidic chloride solutions has been investigated using 3-phenyl-4-acyl-5-isoxazolones in xylene such as 3phenyl-4-benzoyl-5-isoxazolones (HPBI), 3-phenyl-4-(4-fluorobenzoyl)-5-isoxazolone (HFBPI) and 3-phenyl-4-(4-toluoyl)-5-isoxazolone (HTPI). The extraction of zirconium(IV) / hafnium(IV) shows a ion exchange mechanism: $\mathrm{MO}^{2+}$ (a) $)+2 \mathrm{HA}_{\text {(org) }} \leftrightarrow \mathrm{MOA}_{2}$ (org) +2 $\mathrm{H}^{+}$, ${ }^{\text {agi }}$, where $\mathrm{M}=\mathrm{Zr}(\mathrm{IV}) / \mathrm{Hf}(\mathrm{IV})$ and HA $=$ HPBI or HFBPI or HTPI. The variation of the $\mathrm{D}\left(\left[\mathrm{MOA}_{2}\right]_{(\text {org })} /\left[\mathrm{MO}^{2+}\right]_{(\mathrm{aq})}\right.$ ratio of the possible extraction equilibrium species) values with an increase of the acid / extractant concentration showed a linear plot with a slope of 2 . The effect of the nature of the diluents like carbon tetrachloride, cyclohexane, $n$-hexane, benzene, nitrobenzene, xylene, toluene and chloroform on the extraction of zirconium(IV) / hafnium(IV) has been studied. The extraction behavior of zirconium(IV) / hafnium(IV) was also compared with that of other metal ions like titanium(IV), aluminium(III) and iron(III), which can be generally associated with the metal ions studied.

Keywords: 3-phenyl-4-acyl-5-isoxazolones, extraction, zirconium(IV), hafnium(IV), acidic chloride solutions

\section{Introduction}

In analytical chemistry, liquid-liquid extraction (LLE) enjoys a favored position among separation techniques because of its simplicity, speed and wide scope. This method is also frequently used in nuclear chemistry and technology for the separation of various radioisotopes and for the reprocessing of nuclear fuels. Zirconium and hafnium co-exist in nature and are

*e-mail: brcreddy_iict@yahoo.com difficult to separate because of similar chemical properties. In order to achieve these objectives, the zirconium and hafnium metals industry needs to separate the title metals from other associated metals like $\mathrm{Ti}, \mathrm{Fe}, \mathrm{Si}$ and $\mathrm{Al}$ etc.

In our earlier investigations, the extraction behavior $\mathrm{Zr} / \mathrm{Hf}$ from acidic chloride media was studied with organophosporus and oxime based extractants. ${ }^{1-7}$ Isoxazolones are considered as an interesting class of $\beta$-diketones with potential applications as extractants for metal ions complexation from strong acid media 
because of their lower pKa values. ${ }^{8}$ In the present study, substituted isoxazolones such as 3-phenyl-4-benzoyl5-isoxazolone (HPBI), 3-phenyl-4-(4-fluorobenzoyl)5-isoxazolone (HFBPI) and 3-phenyl-4-(4-toluoyl)-5isoxazolone (HTPI) have been explored for $\mathrm{Zr} / \mathrm{Hf}$ extraction from chloride medium.

\section{Experimental}

Reagents

HPBI, HFBPI and HTPI were synthesized from 3-phenyl-5-isoxazolone and corresponding acid chlorides according to the method described elsewhere. ${ }^{9}$ $\mathrm{ZrOCl}_{2} \cdot 8 \mathrm{H}_{2} \mathrm{O}$ and $\mathrm{HfCl}_{4}$ (Fluka, 98\%) were used. Working solutions of zirconium(IV)/ hafnium(IV) were freshly prepared and used for the extraction experiments through out the studies. All other reagents used were analytical reagent grade.

The synthesized 4-acyl-3-phenyl-5-isoxazolones was identified by elemental analysis, IR and ${ }^{1} \mathrm{H}$ NMR spectral data. Recrystallisation of the compounds was carried out in ethyl acetate - hexane mixture.

HPBI. mp $146{ }^{\circ} \mathrm{C} ;{ }^{1} \mathrm{H}$ NMR data: $\delta$ 7.06-7.41 (m, 10H, phenyl); IR (KBr) $v_{\max } / \mathrm{cm}^{-1}: 3062,1701(\mathrm{C}=\mathrm{O}), 1620$, 1489, 834; Elemental analysis: calculated for $\mathrm{C}_{16} \mathrm{H}_{11} \mathrm{NO}_{3}$. C 72.45, H 4.15, N 5.28. Found: C 72.27, $\mathrm{H} 4.18$, N $5.17 \%$.

HFBPI. mp $149{ }^{\circ} \mathrm{C} ;{ }^{1} \mathrm{H}$ NMR data: $\delta$ 6.82-7.39 (m, 9H, phenyl); IR $v_{\max } / \mathrm{cm}^{-1}: 2600,1702(\mathrm{C}=\mathrm{O}), 1620,1583$; Elemental analysis: calculated for $\mathrm{C}_{16} \mathrm{H}_{10} \mathrm{NO}_{3} \mathrm{~F}$. C 67.84, H 3.53, N 4.95. Found: C 67.56, H 4.08, N $4.95 \%$.

HTPI. mp $145{ }^{\circ} \mathrm{C}$; ${ }^{1} \mathrm{H}$ NMR data: $\delta$ 6.77-7.37 (m, 9H, phenyl) 2.31(3H, methyl); IR $v_{\max } / \mathrm{cm}^{-1}: 2600,1699(\mathrm{C}=\mathrm{O})$ 1613, 1600, 830; Elemental analysis: calculated for $\mathrm{C}_{17} \mathrm{H}_{13} \mathrm{NO}_{3} \mathrm{C}, 73.12, \mathrm{H} 4.66, \mathrm{~N}$ 5.02. Found: $\mathrm{C} 73.52, \mathrm{H}$ $4.73, \mathrm{~N} 5.1 \%$.

In the ${ }^{1} \mathrm{H}$ NMR spectrum of HPBI, a peak at $\delta 12.2$ ppm has been observed corresponding to the enolic $-\mathrm{OH}$. On the other hand, no peak was observed for the $-\mathrm{OH}$ in the case of HTPI. However, in the case of HFPBI, a broad peak at $\delta 3.57 \mathrm{ppm}$ has been noted. This signal did not move on changing the concentration and found to disappear with the addition of $\mathrm{D}_{2} \mathrm{O}$, thus confirming the existence of HFBPI in the enolic form. The absence of a peak at $\delta 3.8 \mathrm{ppm}$ corresponding to the methylene proton at the fourth position of the isoxazolone ring, further confirms the existence of various 3-phenyl-4-acl-5isoxazolones in the enolic form.

\section{Apparatus}

The concentration of $\mathrm{Zr}(\mathrm{IV})$ and $\mathrm{Hf}(\mathrm{IV})$ in the aqueous phase was determined by the xylenol orange (XO) method $^{10}$ at $535 \mathrm{~nm}$ and Ti (IV) by hydrogen peroxide ${ }^{10}$ method at $410 \mathrm{~nm}$ using a GBC CINTRA 10e UV- VisDRS spectrometer. Analysis of $\mathrm{Fe}(\mathrm{III})$ and $\mathrm{Al}(\mathrm{III})$ was obtained using Perkin Elmer Model A 300 AAS. The NMR spectrum of the extracted solid comlex was recorded with Avance - $300 \mathrm{MHz}{ }^{1} \mathrm{H}$ NMR instrument. The IR spectrum of the solid complexes was recorded with FTIR-Nicolet (USA)-740- spectrophotometer.

\section{General liquid-liquid extraction procedure}

Equal volumes $(10 \mathrm{~mL})$ of the aqueous phase containing desired concentration of metal and organic phase containing the extractant, were equilibrated for 30 minutes in glass stoppered bottles using a mechanical shaker. Preliminary experiments on the kinetics of metal extraction showed that equilibrium was achieved with in 20 minutes contact. After phase disengagment, the aqueous phase was separated and metal concentrations were estimated by XO method. All the experiments were conducted at room temperature $\left(30 \pm 1{ }^{\circ} \mathrm{C}\right)$ and the general agreement with $\mathrm{D}$ values obtained was within $\pm 5 \%$. The distribution ratio, $\mathrm{D}$ is calculated as the concentration of metal present in the organic phase to that part in the aqueous phase at equilibrium.

\section{Results and Discussion}

\section{Effect of phase contact time}

The effect of phase contact time was studied on the distribution ratio of $0.0005 \mathrm{~mol} \mathrm{~L}^{-1}$ zirconium(IV)/ hafnium(IV) from $0.1 \mathrm{~mol} \mathrm{~L}^{-1}$ hydrochloric acid solutions using $0.001 \mathrm{~mol} \mathrm{~L}^{-1}$ 3-phenyl-4-acyl-5-isoxazolones as the extractants. Distribution ratio increases with increasing phase contact time upto 20 minutes and remains constant thereafter (Figure 1).

\section{Extraction equilibrium and species}

The extraction equilibrium of zirconium(IV)/hafnium(IV) from acidic chloride solutions with 3-phenyl-4-acyl-5isoxazolones as the extractants may be represented as: 


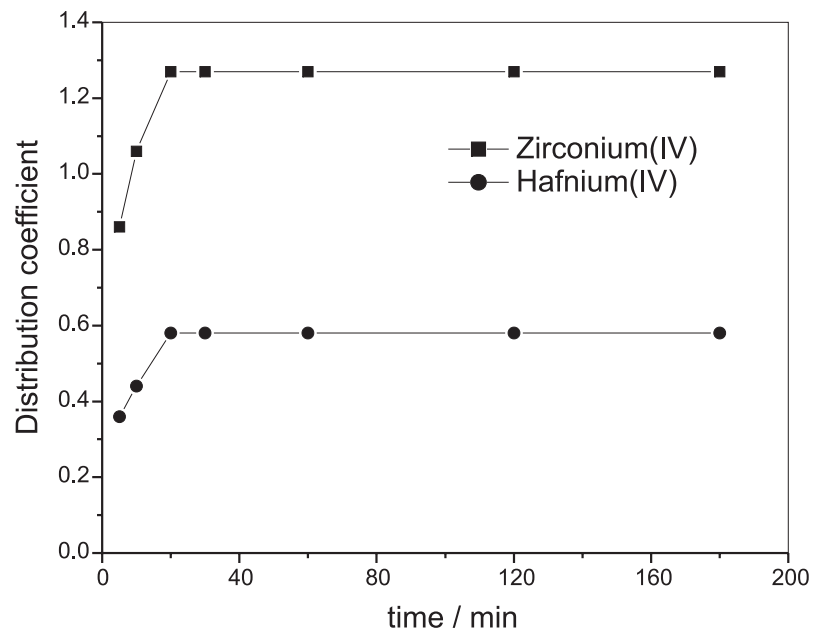

Figure 1. Dependence of distribution ratio on phase contact time. $\mathrm{Zr}(\mathrm{IV}) /$ $\mathrm{Hf}(\mathrm{IV}): 0.0005 \mathrm{~mol} \mathrm{~L}^{-1}, \mathrm{HCl}: 0.1 \mathrm{~mol} \mathrm{~L}^{-1}, \mathrm{HPBI}$ or HFBPI or HTPI: 0.001 mol L-1.

$\mathrm{MO}_{(\mathrm{aq})}^{2+}+2 \mathrm{HA}_{(\mathrm{org})} \stackrel{\mathrm{K}_{\mathrm{ex}}}{\leftrightarrow} \mathrm{MOA}_{2(\mathrm{org})}+2 \mathrm{H}_{(\mathrm{aq})}^{+}$

Where $\mathrm{K}_{\mathrm{ex}}$ denotes the equilibrium constant, $\mathrm{M}$ is equal to zirconium(IV) or hafnium(IV) and HA refers to HPBI or HFBPI or HTPI.

Substituting $\left[\mathrm{MOA}_{2}\right]_{(\mathrm{org})} /\left[\mathrm{MO}^{2+}\right]_{(\mathrm{aq})}$ for $\mathrm{D}$ and rearranging equation (1) becomes

$\log \mathrm{D}=\log \mathrm{K}_{\mathrm{ex}}+2 \log [\mathrm{HA}]-2 \log \left[\mathrm{H}^{+}\right]$

The extraction of $0.0005 \mathrm{~mol} \mathrm{~L}^{-1}$ zirconium(IV) or hafnium(IV) with $0.001 \mathrm{~mol} \mathrm{~L}^{-1}$ 3-phenyl-4-acyl-5isoxazolones in xylene as a function of hydrochloric acid has been studied. The extraction behavior shows an inverse dependence on the acidity (Figure 2). The $\log v s$. $\log$ plots (Figure 3) for zirconium(IV) and hafnium(IV) gave slopes -2 , confirming the formation of simple metal chelates. The results clearly indicate the release of $\mathrm{H}^{+}$ions from the extractant during the extraction process.

The effect of HPBI, HFBPI and HTPI concentrations in the range $4 \times 10^{-3}$ to $1 \times 10^{-3} \mathrm{~mol} \mathrm{~L}^{-1}$ on the extraction of zirconium(IV) and hafnium(IV) has been studied by keeping the metal $\left(0.0005 \mathrm{~mol} \mathrm{~L}^{-1}\right)$ and hydrochloric acid concentrations $\left(0.1 \mathrm{~mol} \mathrm{~L}^{-1}\right)$ constant. It is clear from the results that the extraction of both $\mathrm{Zr}$ (IV) and $\mathrm{Hf}(\mathrm{IV})$ increases with increase in concentrations of 3-phenyl-4-acyl-5-isoxazolones (HA). The log vs. $\log$ plots gave slopes of 2 , indicating extraction of the complex, $\mathrm{MOA}_{2}(\mathrm{M}=\mathrm{Zr}(\mathrm{IV})$ or $\mathrm{Hf}(\mathrm{IV})$ (Figure 4).

The effect of metal ion concentration on the extraction of zirconium(IV)/hafnium(IV) (0.0001-0.001 mol L-1) from hydrochloric acid solutions $\left(0.1 \mathrm{~mol} \mathrm{~L}^{-1}\right)$
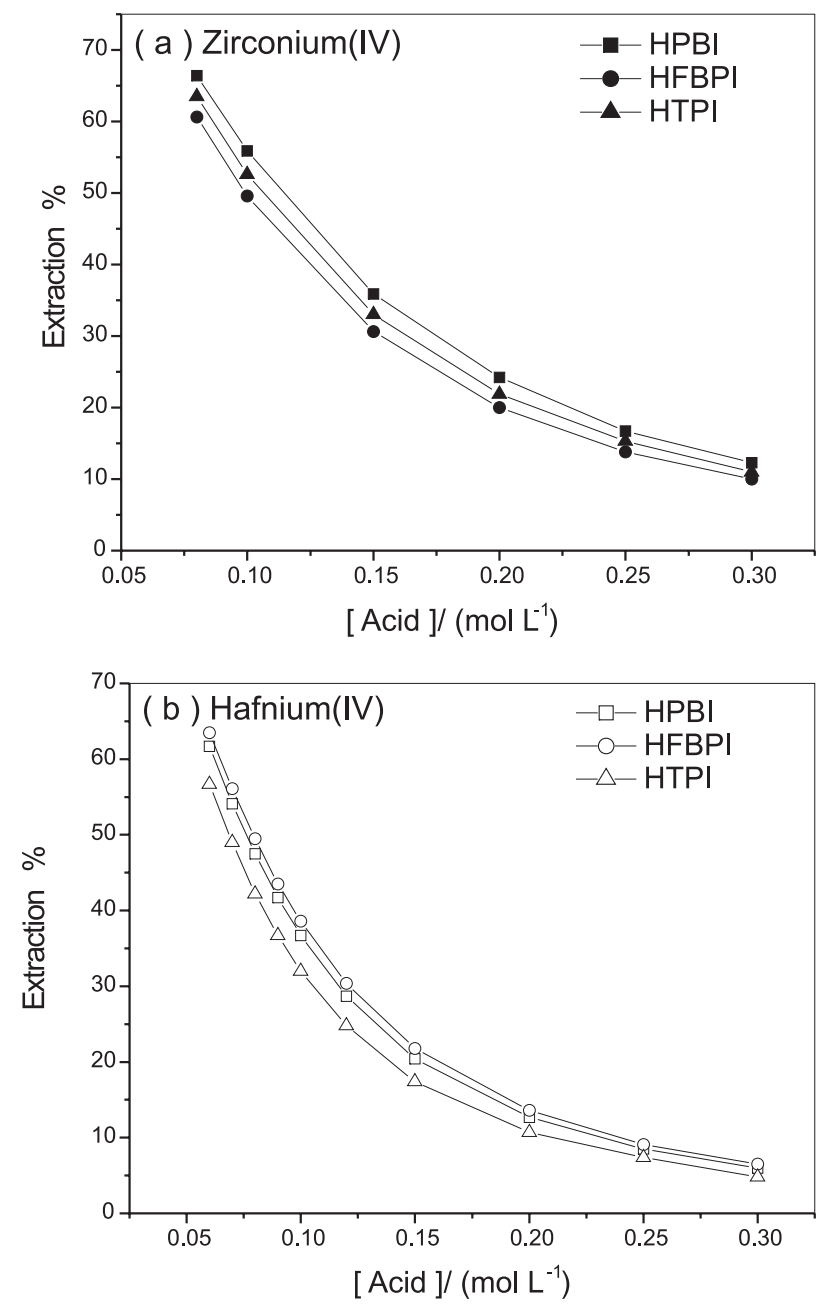

Figure 2. Effect of hydrochloric acid concentration on the extraction of zirconium(IV)/ hafnium(IV). Zr(IV) or Hf(IV): $0.0005 \mathrm{~mol} \mathrm{~L}^{-1}$, HPBI or HFBPI or HTPI: $0.001 \mathrm{~mol} \mathrm{~L}^{-1}$.

using various 3-phenyl-4-acyl-5-isoxazolones (0.001 mol $\left.\mathrm{L}^{-1}\right)$ has been investigated and the results are shown in Figure 5. It has been observed that the extraction of $\mathrm{Zr}(\mathrm{IV})$ and Hf(IV) were found to be independent of metal ion concentrations in the studied range. The log-log plots of equilibrium organic phase metal concentrations to the aqueous phase metal concentrations are linear with slopes of unity, indicating the extraction of mononuclear species into the organic phase.

Based on these studies, the extracted species of $\mathrm{Zr}(\mathrm{IV})$ or Hf(IV) from hydrochloric acid solutions with 3-phenyl-4-acyl-5-isoxazolones (HA) may be represented as $\mathrm{MOA}_{2}(\mathrm{M}=\mathrm{Zr}(\mathrm{IV}) / \mathrm{Hf}(\mathrm{IV}))$.

\section{Effect of diluents}

The differences in extractive properties of an extractant in various diluents are usually ascribed to a 

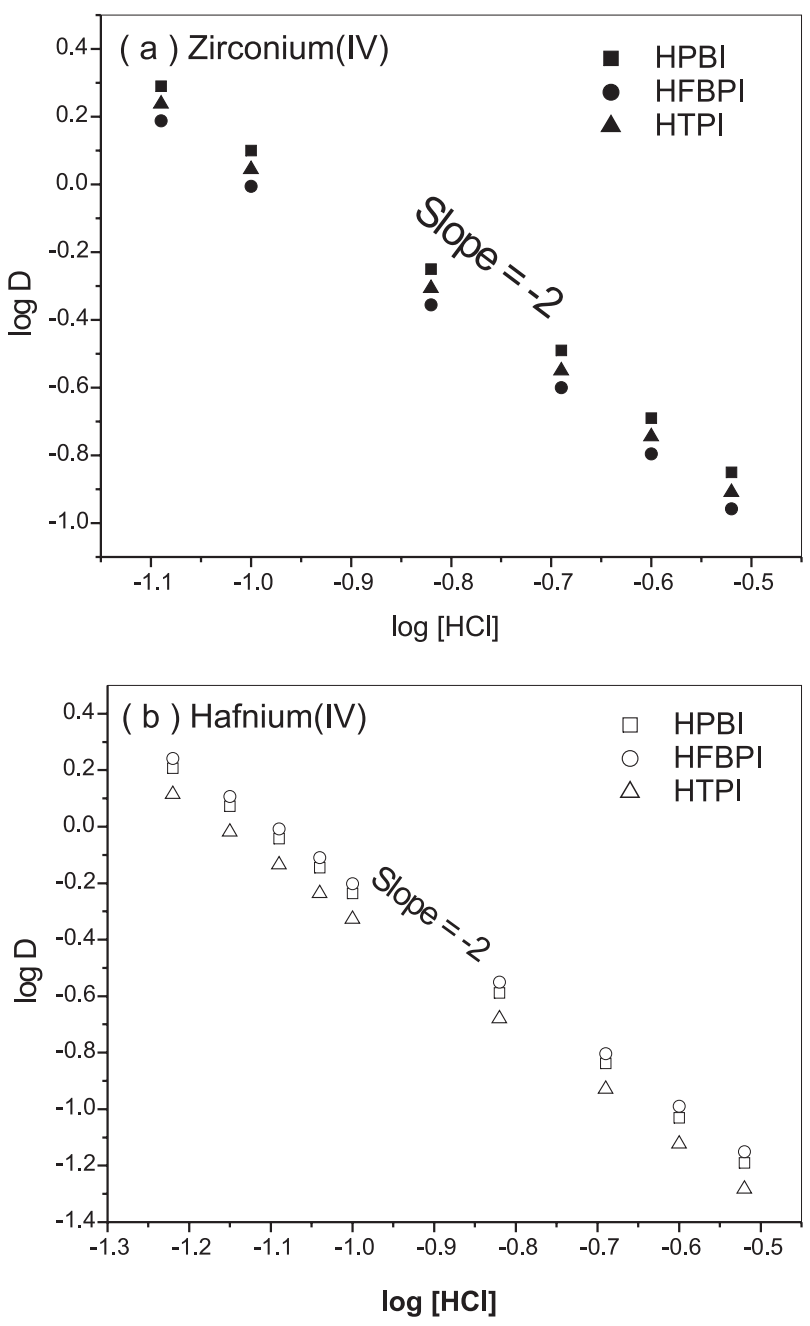

Figure 3. Plots of $\log \mathrm{D}$ vs. $\log [\mathrm{HCl}], \mathrm{mol} \mathrm{L}^{-1}$. $\mathrm{Zr}(\mathrm{IV})$ or $\mathrm{Hf}(\mathrm{IV}): 0.0005$ mol L-1, HPBI or HFBPI or HTPI: $0.001 \mathrm{~mol} \mathrm{~L}^{-1}$.

varying extent of non-ideality of the solutes, the free extractant and its metal salt adduct, in the diluent. A quantitative determination of these effects is at present hardly, possible, because of the lack of data on the physico-chemical properties of the systems. The extraction of zirconium(IV)/hafnium(IV) $(0.0005 \mathrm{~mol}$ $\mathrm{L}^{-1}$ ) from $0.1 \mathrm{~mol} \mathrm{~L}^{-1}$ hydrochloric acid solutions with $0.001 \mathrm{~mol} \mathrm{~L}^{-1}$ HPBI using various diluents has been studied. The results indicate that the extraction of $\mathrm{Zr}(\mathrm{IV})$ or $\mathrm{Hf}(\mathrm{IV})$ varies with the nature of diluents and follows the order (\% E): carbon tetrachloride $(70.2)>$ cyclohexane (64.5) $>n$-hexane, benzene $(59.3)>$ nitrobenzene $(56.5)>$ xylene $(55.9)>$ toluene $(53.7)>$ chloroform (51) for zirconium(IV) and carbon tetrachloride $(58.7)>$ cyclohexane $(52.4)>n$-hexane (48.7) $>$ nitrobenzene (42.9) $>$ benzene (41.9) $>$ toluene (39) $>$ xylene (36.7) > chloroform (34.2) for hafnium(IV).
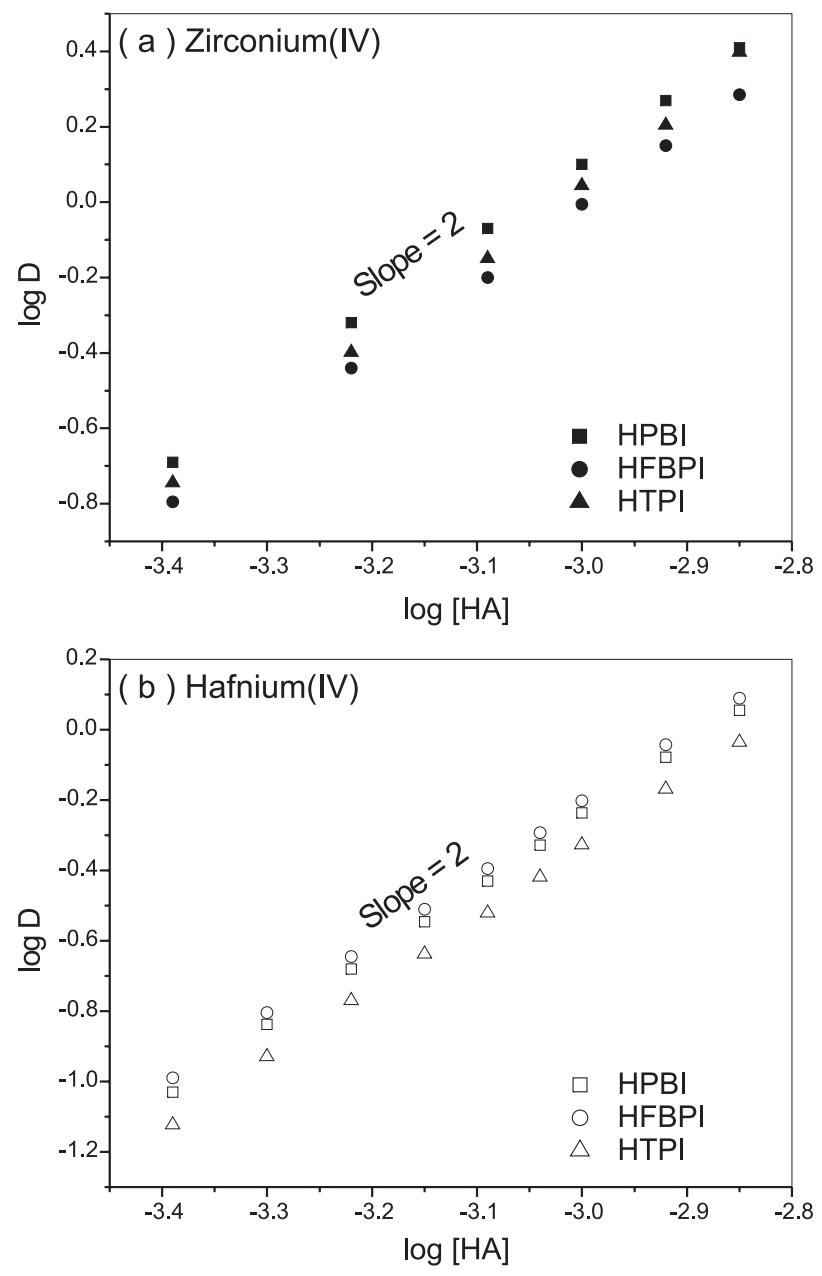

Figure 4. Plots of $\log \mathrm{D}$ vs. $\log [\mathrm{HA}], \mathrm{mol} \mathrm{L}^{-1}$. Zr(IV) or $\mathrm{Hf}(\mathrm{IV}): 0.0005$ mol L ${ }^{-1}, \mathrm{HCl}: 0.1 \mathrm{~mol} \mathrm{~L}^{-1}$.

\section{Effect of associated metal ions}

The extraction behavior of zirconium(IV), hafnium (IV), titanium(IV), aluminium(III) and iron(III) (0.0005 mol L-1 each) has been investigated as a function of hydrochloric acid concentration using $0.001 \mathrm{~mol} \mathrm{~L}^{-1}$ HPBI in xylene as an extractant (Figure 6). The results indicate that the percentage extraction of $\operatorname{Ti}(\mathrm{IV})$ and $\mathrm{Al}(\mathrm{III})$ is quantitative under the present experimental conditions. On the other hand, $\mathrm{Zr}(\mathrm{IV}), \mathrm{Hf}(\mathrm{IV})$ and $\mathrm{Fe}(\mathrm{III})$ extraction decreases with increasing acid concentration.

\section{Conclusions}

The extraction behavior of zirconium(IV)/ hafnium(IV) has been investigated using 3-phenyl-4acyl-5-isoxazolones such as HPBI, HFBPI and HTPI 

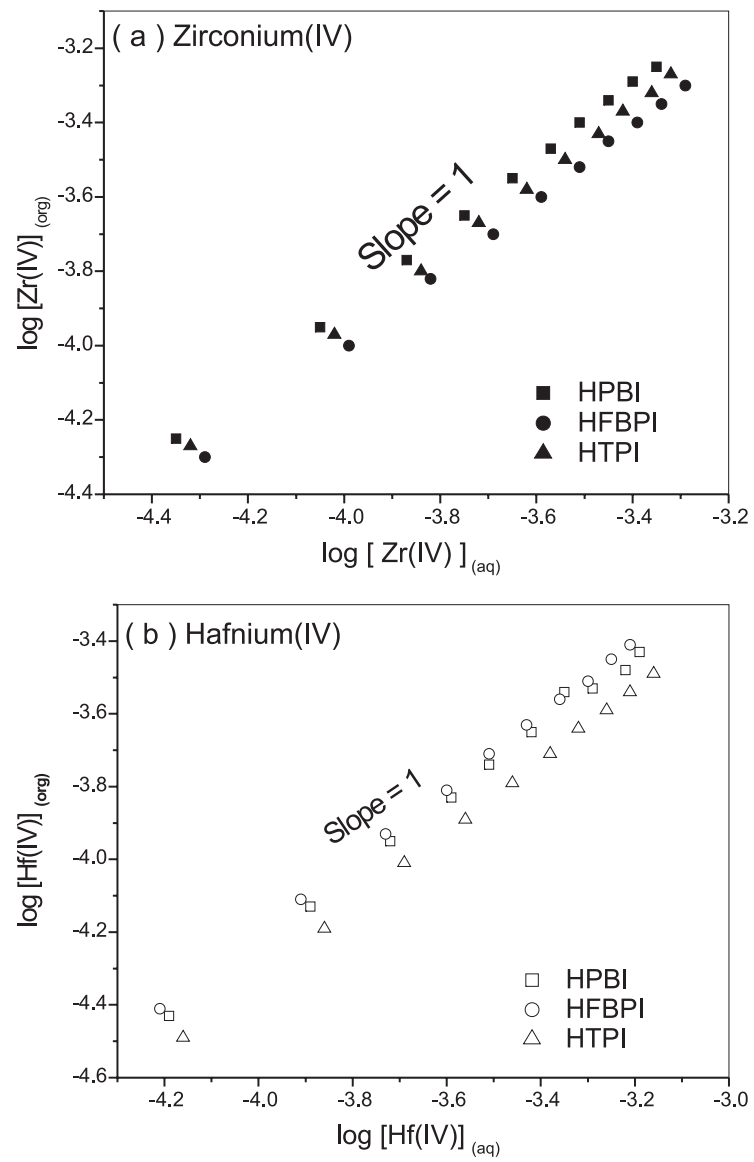

Figure 5. Effect of metal concentration on the extraction of zirconium(IV) / hafnium(IV). $\mathrm{HCl}$ : $0.1 \mathrm{~mol} \mathrm{~L}^{-1}$, HPBI or HFBPI or HTPI: $0.001 \mathrm{~mol} \mathrm{~L}^{-1}$.

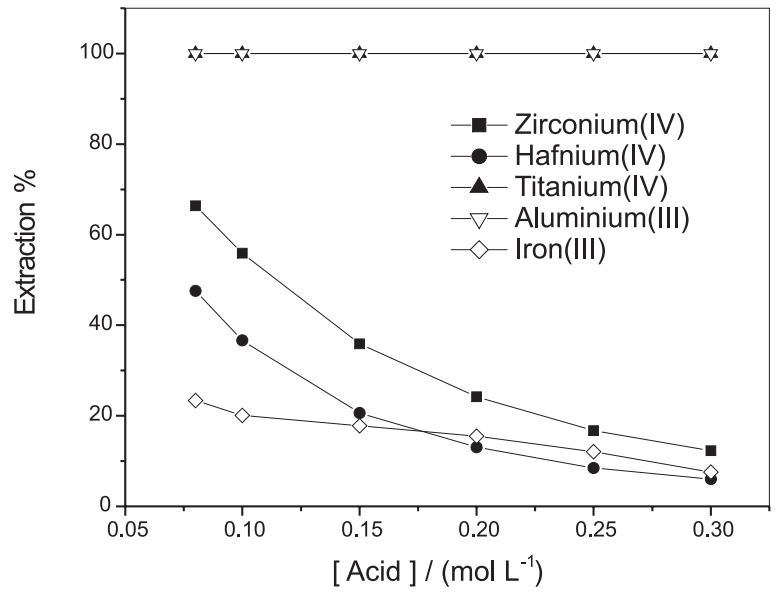

Figure 6. Effect of hydrochloric acid concentration on the extraction of associated metals. Metal: $0.0005 \mathrm{~mol} \mathrm{~L}^{-1}$, HPBI: $0.001 \mathrm{~mol} \mathrm{~L}^{-1}$. in xylene. The present study on LLE of $\mathrm{Zr}(\mathrm{IV}) / \mathrm{Hf}(\mathrm{IV})$ from acidic chloride solutions by HPBI revealed the transfer of metal by cation exchange mechanism. The extraction efficiency of zirconium(IV) / hafnium(IV) with various HPBI reagents follow the order HPBI $>$ HTPI $>$ HFBPI for Zr(IV) and HFBPI $>$ HPBI $>$ HTPI for $\mathrm{Hf}(\mathrm{IV})$. Variation of $\mathrm{D}$ values with increase of extractant concentration showed linear plots with slope of 2, indicating that the species extracted as $\mathrm{MOA}_{2}(\mathrm{M}$ $=\mathrm{Zr}(\mathrm{IV})$ or $\mathrm{Hf}(\mathrm{IV}))$.

\section{Acknowledgments}

J. Rajesh Kumar is grateful to Council of Scientific \& Industrial Research (CSIR), Government of India, New Delhi, for financial assistance in the form of Senior Research Fellowship.

\section{References}

1. Reddy, B. R.; Kumar, J. R.; Reddy, A. V.; Priya, D. N.; Hydrometallurgy 2004, 72, 303.

2. Reddy, B.R.; Kumar, J.R.; Reddy, A.V.; Miner. Eng. 2004, 17, 553

3. Reddy, B. R.; Kumar, J. R.; Reddy, A. V.; Anal. Sci. 2004, 20, 501

4. Reddy, B. R.; Kumar, J. R.; Reddy, A. V.; Hydrometallurgy 2004, 74, 173.

5. Reddy, B. R.; Kumar, J. R.; Raja, K. P.; Reddy, A. V.; Miner Eng. 2004, 17, 939

6. Reddy, B. R.; Kumar, J. R.; Reddy, A. V.; J. Chem. Technol. Biotechnol. 2004, 79, 1301

7. Reddy, B. R.; Kumar, J. R.; Sep. Purif. Technol. 2004, 42, 169.

8. Remya, P. N.; Pavithran, R.; Reddy, M. L. P.; Solvent Extr. Ion Exch. 2004, 22, 473.

9. Kamm, O.; Marvel, C. S.; J. Am. Chem. Soc. 1920, 42, 299.

10. Marczenko, Z.; Spectrophotometric Determination of Elements, John Wiley \& Sons: New york, 1976, pp. 555, 609.

Received: October 20, 2005 Published on the web: June 6, 2006 